\title{
Effects of hydraulic engineering restoration measures on invasive gobies in a large river (Danube, Austria)
}

\author{
David Ramler (1) • Hubert Keckeis (i)
}

Received: 28 June 2018/ Accepted: 25 September 2019/Published online: 29 September 2019

(C) The Author(s) 2019

\begin{abstract}
Invasive gobies can have severe detrimental effects on local fish communities, however, direct methods for population control are often insufficient (i.e. fishing) or not feasible (i.e. poisoning). Indirect methods, such as habitat modifications in the course of restoration programs, appear promising but are poorly studied. In this study, we investigate the effects of different restoration measures on the abundance and occurrence of non-native gobies in the main stem of a free-flowing section of the Danube and attempt to disentangle these measures from general large-scale trends by applying a Before-After-Control-Impact design. We found three invasive goby species (racer, bighead, and round goby) in the sampling area, partly with very high abundances. Four to six years after the installation, the measures had negative (riprap removal), neutral (side arm reconnection), or positive (groyne field adaptations) effects on goby abundances. We conclude that the impact of the measures depends on the type of intervention, is species-specific, and is largely related to substrate composition. Independent from the effect of the measures, abundances of
\end{abstract}

Electronic supplementary material The online version of this article (https://doi.org/10.1007/s10530-019-02101-x) contains supplementary material, which is available to authorized users.

D. Ramler $(\bowtie) \cdot$ H. Keckeis

Department of Limnology and Bio-Oceanography,

University of Vienna, Vienna, Austria

e-mail: david.ramler@univie.ac.at bighead and round goby dropped in the project and reference sections after the pre-survey. This general decline probably indicates a stabilization phase of the goby populations on a lower level, but may also be influenced by a major flood event. Nevertheless, our results indicate a high potential of shoreline modifications for invasive species control, calling for considering and incorporating them in river restoration programs.

Keywords BACI - Bank restoration - Groyne adaptation · Riprap removal · Side arm reconnection · Side channel construction

\section{Introduction}

Since about 3 decades, several goby species (Teleostei: Gobiidae) of Ponto-Caspian origin are spreading over Europe and North-America (Ahnelt et al. 1998; Kornis et al. 2012; Ricciardi and MacIsaac 2000). Today, all major European waterways are invaded by one or more goby species (Borcherding et al. 2011; Kornis et al. 2012; Roche et al. 2013). Rapid dispersal is driven by a mix of long-range introductions via ballast water and active short-range migrations. It is also facilitated by river modifications, such as straightened shores with riprap-reinforced banks (Gozlan et al. 2010; Kornis et al. 2012; Roche et al. 2013). 
While most of the ecological functions of the natural banks were lost, these artificial, largely uninhabited structures match the habitat preferences of many goby species, further promoting their expansion. Different goby species may be dominant in different river stretches based on temporal (e.g. first arrival, duration of invasion) and autecological (e.g. habitat preference, reproduction strategy) traits (Borcherding et al. 2013; Erōs et al. 2005; Kováč et al. 2009; Roche et al. 2013). Gobies can reach very high abundances within a very short time after settling and are therefore among the most abundant fishes in many invaded rivers (Borcherding et al. 2011; Loisl et al. 2014; Szalóky et al. 2015). Scientists soon raised concerns about the negative effects on native species (Charlebois et al. 2001; Janssen and Jude 2001; Ricciardi and MacIsaac 2000), although later studies also showed neutral or even positive effects (Janáč et al. 2016; Kornis et al. 2013; Piria et al. 2016; Płachocki et al. 2012). Nevertheless, field observations and laboratory experiments continue to show that local fish populations may be at risk by goby invasions (Brandner et al. 2013; Jermacz et al. 2015; Števove and Kováč 2016; van Kessel et al. 2011). Therefore, the protection of characteristic or endangered fish species also calls for control measures on goby populations (i.e. reduction of abundance) and for preventing new introductions. In heavily used European waterways such as the Danube or Rhine, however, new introductions are virtually unpreventable, and direct interventions on goby abundances are insufficient, costly and laborintensive, or come at unintentional, high ecological costs (Kornis et al. 2012; N'Guyen et al. 2018).

More promising, but poorly studied, are indirect methods such as habitat modifications in the course of restoration programs (e.g. Dorenbosch et al. 2017). Invasive gobies are opportunistic generalists that can cope with a wide range of ecological conditions, but they also show species-specific preferences for certain habitats (Ahnelt et al. 1998; Borcherding et al. 2013; Didenko 2013; Jakubčinová et al. 2017). Rocky habitats in particular are readily colonized by bighead and round gobies, two of the most widespread invasive species, and the ever increasing proportion of shores stabilized by riprap contributes significantly to their invasion success (Polačik et al. 2008; Ray and Corkum 2001; Wiesner 2005). Consequently, although primarily targeted at promoting native fishes, restoration measures have also a high potential for limiting the spread and abundance of non-native gobies.

One of the largest river restoration projects in Central Europe is the "Integrated River Engineering Project" (IREP), which will be carried out along the free-flowing stretch of the Danube east of Vienna. The IREP has an inter-disciplinary approach and is designed to integrate improvements for navigation, hydraulic engineering, and ecological restoration (Reckendorfer et al. 2005). A pilot project to test several hydraulic engineering measures is already being implemented. It is accompanied by a large-scale monitoring program including scientific investigations with extensive sampling efforts before and after the measures, incorporating the pilot project section as well as unchanged reference sections. From a fishecological point of view, the focus of the pilot project, and the IREP as a whole, is to improve conditions for characteristic and endangered fluvial fish species. Importantly, the sampling design also enables an indepth examination of general trends of the total fish assemblage and the invasive species pool, as well as autecological characteristics of occurring species.

To our knowledge, this is one of the first studies to simultaneously investigate the effects of several different types of shoreline and river modifications on the occurrence and abundance of invasive species in a large river. Herein, we address the following research questions: Which non-native goby species occur in the study area and how abundant are they? What are their habitat preferences? How does each goby species respond to the different restoration measures? Specifically, we assume [1] that, as invasions are strongly facilitated by artificial banks made of rubble (riprap), measures that are accompanied by an exchange of this substrate type have a higher impact than measures that only change abiotic parameters, such as flow velocity or water depth; and [2] that due to differences in habitat/substrate preference, the restoration measures will have different effects on the respective goby species. The outcome of this study will contribute to the handling options for population control of invasive goby species and serves as a basis for future restoration projects. 


\section{Methods}

\section{General}

Sampling was carried out in the Danube east (downstream) of Vienna, between river kilometers 1893.5 to 1880.5, close to the Slovakian border (Fig. 1). This stretch is a part of the "Alluvial Zone National Park" (Nationalpark Donau-Auen) which is, although impacted by river engineering measures, one of the two last remaining free-flowing sections of the Austrian Danube. Within this stretch, we sampled three sections: the project section near Bad DeutschAltenburg in which the restoration measures of the pilot project of the IREP were implemented and two reference sections near Witzelsdorf and Hainburg. Sampling took place before the measures in 2006/07 (termed "pre-survey"), shortly afterwards in 2014/15 ("post-survey 1"), and again in 2017 ("post-survey 2"). Sampling periods extended from March to December, each section being sampled twice a month from March to May and once a month afterwards. The initially designated reference section in Witzelsdorf

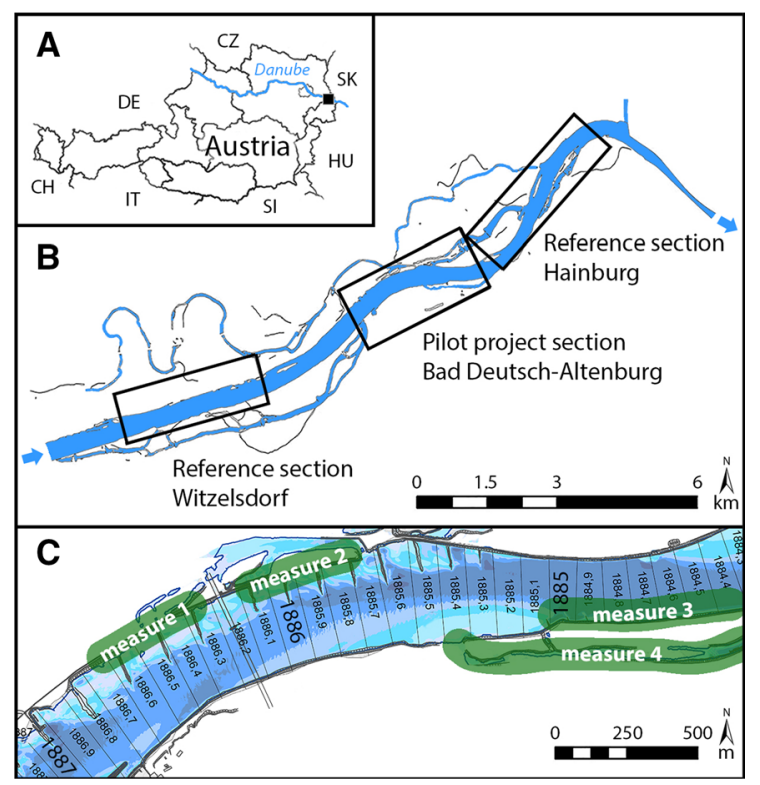

Fig. 1 Sampling area of the pilot project of the Integrated River Engineering Project. a Map of Austria with black rectangle indicating sampled section. b Sampling area with pilot project and reference sections. Arrows indicate direction of flow. c Close-up of the project section showing the location of the measures (see text for details). The numbers indicate the river kilometer; shades of blue water depth had to be changed due to unforeseeable water engineering emergency measures within this section shortly after the pre-survey. Nonetheless, samples taken at the same time during a 3-month period show that the mesohabitats in both references are similar enough (e.g. regarding choriotope structure, abiotic parameters, species composition) to be combined (see also Loisl et al. 2014). Accordingly, overlapping months were treated as replicates.

\section{Mesohabitats and restoration measures}

We assigned river stretches to five a priori defined characteristic mesohabitat types: riprap, groynefield, gravel bar, side arm, and side channel. They were classified visually based on structural and hydromorphological conditions of the shoreline and are the basis of the sampling design and comparisons. All mesohabitat types were represented at least once in each section.

The restoration efforts of the pilot project span over $3 \mathrm{~km}$ and included four river engineering measures with a modified length ranging from ca. 500 to $1200 \mathrm{~m}$ (Table 1; see also Reckendorfer et al. 2005): [1] groyne adaptation I: side channel formation by removing the inshore parts of a groynefield section and constructing a gravel island; [2] groyne adaptation II: groynefield adaptation by cutting groynes at their roots to enable a bank-side flow, lowering the groyne height and declinant positioning; [3] bank restoration: removal of riprap and new construction/extension of a gravel bar; [4] side arm reconnection: reconnection of a former side arm to the main stem of the Danube. The first two measures may be seen as two types of groynefield adaptations of different intensity: the flow velocity is increased in both concerned mesohabitats, but in one (measure 1) also the substrate is changed to more natural conditions (from riprap to small stones and finer substrate), while the other (measure 2) remains highly artificial.

The mesohabitats sampled as side arms in the reference were bay-like remnants of former inlets of now disconnected side arms and were characterized by lentic conditions. Thus, they correspond to the side arm in the project section prior to reconnection. Generally, the mesohabitat types that were sampled as references always correspond to the mesohabitats in the project section before the measure have been implemented (Table 1). In addition to the 
Table 1 Evaluated measures and sampling effort

\begin{tabular}{|c|c|c|c|c|c|c|c|c|c|c|c|}
\hline & \multirow[t]{2}{*}{ Measure } & \multirow{2}{*}{$\begin{array}{l}\text { Mesohabitat } \\
\text { before }\end{array}$} & & \multirow{2}{*}{$\begin{array}{l}\text { Mesohabitat } \\
\text { after }\end{array}$} & \multirow{2}{*}{$\begin{array}{l}\text { Modified length } \\
\text { (m) }\end{array}$} & \multicolumn{3}{|c|}{ Project section } & \multicolumn{3}{|c|}{ Reference section } \\
\hline & & & & & & PRE & POST1 & POST2 & PRE & POST1 & POST2 \\
\hline \multicolumn{12}{|c|}{ Wading electrofishing_littoral zone } \\
\hline [1] & $\begin{array}{l}\text { Groyne } \\
\text { adaptations I }\end{array}$ & Groynefield & $>$ & Side channel & 500 & 12 & 11 & 12 & $24 / 6$ & $6 / 22$ & $0 / 24$ \\
\hline [2] & $\begin{array}{l}\text { Groyne } \\
\text { adaptations II }\end{array}$ & Groynefield & $>$ & $\begin{array}{l}\text { Mod. } \\
\text { groynefield }\end{array}$ & 500 & 12 & 12 & 12 & $24 / 6$ & $6 / 22$ & $0 / 24$ \\
\hline [3] & Bank restoration & Riprap & $>$ & Gravel bar & 800 & 12 & 12 & 12 & $12 / 3$ & $3 / 12$ & $0 / 12$ \\
\hline [4] & $\begin{array}{l}\text { Side arm } \\
\text { reconnection }\end{array}$ & $\begin{array}{l}\text { Lentic side } \\
\text { arm }\end{array}$ & $>$ & $\begin{array}{l}\text { Lotic side } \\
\text { arm }\end{array}$ & 1200 & 12 & 12 & 12 & $12 / 3$ & $3 / 12$ & $0 / 12$ \\
\hline \multicolumn{12}{|c|}{ Longline sampling_-benthic zone } \\
\hline [2] & $\begin{array}{l}\text { Groyne } \\
\text { adaptations II }\end{array}$ & Groynefield & $>$ & $\begin{array}{l}\text { Mod. } \\
\text { groynefield }\end{array}$ & 500 & 11 & 9 & 12 & $22 / 6$ & $3 / 12$ & $0 / 24$ \\
\hline [4] & $\begin{array}{l}\text { Side arm } \\
\text { reconnection }\end{array}$ & $\begin{array}{l}\text { Lentic side } \\
\text { arm }\end{array}$ & $>$ & $\begin{array}{l}\text { Lotic side } \\
\text { arm }\end{array}$ & 1200 & 11 & 12 & 12 & $7 / 3$ & $3 / 13$ & $0 / 12$ \\
\hline
\end{tabular}

The mesohabitat sampled in the reference section always corresponds to the mesohabitat in the project section before the measure was implemented. Modified length gives the approximate length of the modified river stretch for each measure. Sampling effort is expressed as the number of temporal replicates (i.e. sampling dates) for each survey. Sampling effort in the reference is given in the order Witzelsdorf/Hainburg (see text for further details). PRE—pre-survey in 2006/07; POST1-post-survey 1 in 2014/15; POST2post-survey 2 in 2017

mesohabitats used for the analyses of the restoration measures, we have also sampled additional (unmodified) mesohabitats in the project and reference section to address more basic general questions like, for instance, habitat preferences of gobies.

\section{Sampling}

Fishes were caught using wading electrofishing and longline sampling. Electrofishing is a reliable and often used method for sampling the inshore fish coenosis (littoral zone), while longline sampling targets offshore, bottom-dwelling fishes (benthic zone; Kubečka et al. 2012; Loisl et al. 2014). The fish monitoring program of the pilot project also included electrofishing from a boat but, due their benthic life style, gobies were only rarely caught with this method (ca. $1 \%$ of total goby catch), impeding any detailed analyses. Electrofishing was carried out in all five mesohabitats in each section using stationary electrofishing equipment ( $3 \mathrm{~kW}, 300 / 500 \mathrm{~V}, 13 / 9 \mathrm{~A}$; EL62II Hans Grassl GmbH). Mesohabitats were divided in five transects of $20 \mathrm{~m}$ length, which were treated as replicates. Longlines were laid in three mesohabitat types in each section (groynefield, gravel bar, side arm). Longline sampling was not applicable in the riprap mesohabitats due to very high flow velocities, which dislocated the lines, as well as in the side channel due to low water levels. Each longline was approximately $50 \mathrm{~m}$ long, with one hook on a trace every meter. We used hooks of sizes 4,6 , and 8 , baited with worms or maggots. Lines were laid in the morning and remained in the water overnight (mean exposure time $22.0 \pm 1.6 \mathrm{~h}$ ). All caught fish were measured (total length) to the nearest millimeter, identified at species level, and released again (see also Loisl et al. 2014; or Ramler and Keckeis 2018 for details on sampling methods).

Throughout all surveys, we measured water temperature and conductivity and estimated the choriotope structure (electrofishing only). To better characterize the mesohabitats, we calculated a relative water temperature, which we defined as the difference of the water temperature measured by us within a mesohabitat and the daily mean water temperature measured at a hydrological station. During the postsurveys, we also measured water depth and flow velocity (electrofishing only). Additional information on water level, discharge, and water temperature of the Danube was provided by the federal waterway 
operator (viadonau) from the nearest hydrological stations in Wildungsmauer and Hainburg.

Data analysis

To assess the sediment composition, the choriotope structure was estimated following Moog et al. (1999). In order to determine if this structure truly corresponds to the mesohabitat types, we visually compared the proportions of choriotope types for all sections and sampling years and performed principal component analyses (PCA), also including other abiotic parameters. For details on PCAs and further analyses concerning choriotope structure see Online Resource 1.

All abundance data were standardized to catchper-unit-effort (CPUE) values by dividing the number of caught fish by the sampling duration. For the statistical analyses, abundance data were normalized by the $\log$-transformation $b=\log (x+d)-c$, in which $x$ is the original CPUE value, $d$ a decimal constant, and $c$ a constant indicating the order of magnitude (following McCune et al. 2002). Size data was normalized by a square root transformation. For better interpretation, untransformed data are shown in the figures.

To disentangle the effects of the measures from general large-scale trends, we used a Before-AfterControl-Impact design (BACI; Smith 2002) in which we compared mesohabitats in the project section before and after the measures and against the corresponding mesohabitats in a reference section. To analyze the overall effect of the measures and abiotic parameters on goby abundance we conducted a general linear model with the log-transformed CPUE values of all three goby species as response variables, section (project vs reference section), survey (pre- vs postsurveys), and mesohabitat (riprap, groynefield, gravel bar, side arm, side channel) as factors, discharge and water temperature as covariates, and sampling month as a random variable. Furthermore, general linear models were conducted for each measure using the logtransformed CPUE values of all three goby species as response variables, section and survey as factors, and sampling month as a random variable. An additional general linear model was conducted to analyze the effect of the measures on goby size in the littoral zone, with square root-transformed total lengths of bighead and round goby as response variables and section and survey as factors. Statistical significance of the effects of the respective measures on goby abundance or size are revealed by the interaction term section $\mathrm{x}$ survey (Mahlum et al. 2018). The level of significance was set at $5 \%$. Statistical analyses were conducted using IBM SPSS Statistics 23 (C) IBM Corporation, Armonk, NY).

\section{Results}

\section{General}

All mesohabitat types showed a characteristic and consistent composition of choriotope classes (Online Resource 1), irrespective of section and sampling year. A gradient of decreasing grain size is apparent from ripraps to groynefields to gravel bars. Side arms and side channels shared many similarities, in particular a high proportion of sand, mud, and soil; they also had the highest amounts of macrophytes and deadwood of all mesohabitat types. Side channels were, however, more strongly correlated to stony substrates than were side arms. In the project section, average water temperature values dropped substantially in the side arm after the reconnection, due to the flowing conditions. The groyne modifications led to increased variability in water temperature and partially also in conductivity (Online Resource 2). Among the mesohabitats, high flow velocities were found in gravel bars and ripraps, the lowest in side arms. Lowest relative water temperatures were measured in ripraps.

Three invasive goby species were caught: racer goby Babka gymnotrachelus (Kessler, 1857), bighead goby Ponticola kessleri (Günther, 1861), and round goby Neogobius melanostomus (Pallas, 1814). Round and bighead goby were found in very high numbers (up to 4 individuals per minute), especially during the presurvey (Fig. 2). For each sampling year and method, they comprised between 23 and 54\% of the total catch and more than $96 \%$ of the total catch of non-native species. Round and bighead gobies were and are among the most abundant fishes in the sampling area. Only one native species, the bleak Alburnus alburnus, was caught more often (Ramler and Keckeis 2018). Another member of the Gobiidae was the tubenose goby Proterorhinus semilunaris (Heckel, 1837), which is native in this part of the Danube (Ahnelt 1988) and is therefore not further discussed here. Bighead and round 
A

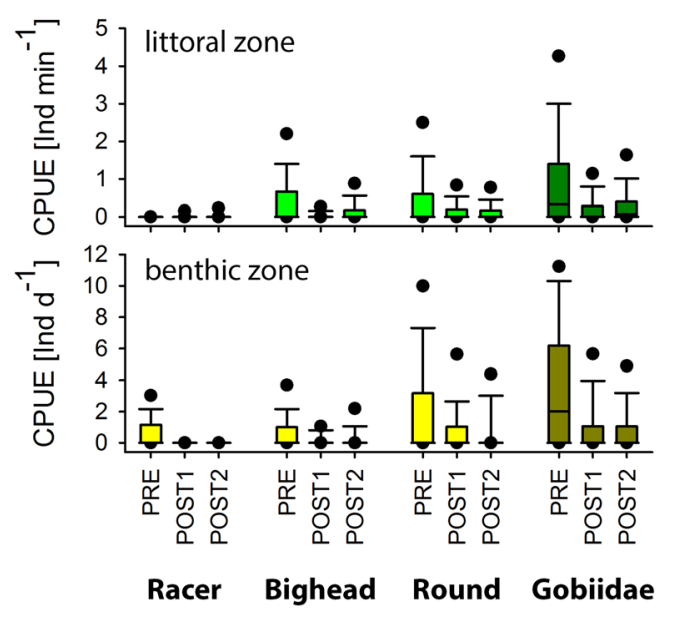

Fig. 2 Changes of goby abundance throughout the surveys. a Total abundances across all mesohabitats for all goby species in the littoral (green, upper diagram) and benthic zone (yellow, lower diagram). b Changes in abundance and composition of

goby showed substantial declines in both sampling methods in post-survey 1 compared to the pre-survey (Fig. 2). This decline is expressed in the project and reference sections and constitutes the sharpest decrease in numbers of all occurring fish species. Bighead goby abundances increased slightly again in post-survey 2, while round goby abundances continued to drop, although at much lower rates. Racer goby abundance was generally low and remained constant through all surveys. In round and racer goby, changes in abundance were reflected in all size classes. In bighead goby, however, the size classes declined or increased disproportionally. As a result, medium-sized fishes constituted $90 \%$ of the total catch of bighead gobies in the latest survey in contrast to a more balanced size distribution in the pre-survey (Fig. 2b).

All gobies showed distinct preferences for certain mesohabitats (Online Resource 3). Round and bighead goby primarily utilized mesohabitats with coarse substrate (riprap and groynefields), while racer goby used mainly mesohabitats characterized by fine sediment (side arm and side channel). The proportion of round gobies in the benthic zone was between 10 and $20 \%$ higher compared to the littoral zone (Online Resource $4 \mathrm{~A})$.

In the littoral zone, discharge had a significant effect on overall abundance for all goby species. This also applies to water temperature, with the
B

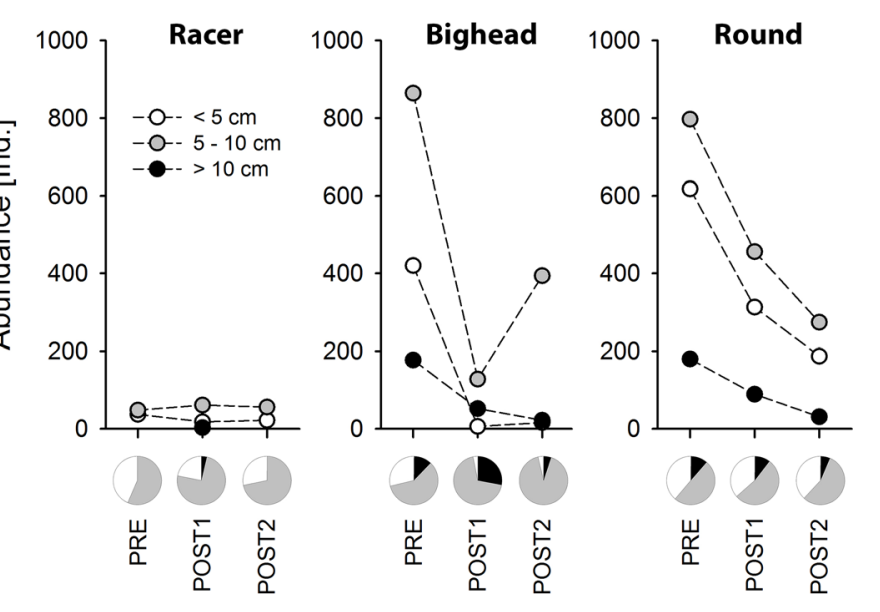

different size-classes of gobies. PRE-pre-survey in 2006/07; POST1-post-survey 1 in 2014/15; POST2-post-survey 2 in 2017

exception of racer goby. No significant effect of discharge or water temperature was found in the benthic zone (Table 2). Also sampling month had a significant effect on overall goby abundance in the littoral zone, but only for bighead goby in the benthic zone (Table 2). The effect of sampling month within the measures was, however, highly variable (Table 3).

\section{Effects of restoration measures}

The four restoration measures had different effects on goby abundances (Figs. 3, 4). Generally, the groyne adaptations (measures $1+2$ ), showed similar developments in abundance in the benthic and littoral zone. Contrary to the substantial decline in the reference section, the abundances of all goby species were on a comparable level during the pre-survey and postsurvey 2 in measure 1 (side channel) and 2 (modified groynefield). However, all goby species had their lowest abundances during post-survey 1 in measure 1; bighead goby also in measure 2. A significant interaction term (section $\mathrm{x}$ survey) was found for both measures for round goby in the littoral zone (Table 3 ). The bank restoration (measure 3) was followed by decreased abundances for bighead and round goby. Significantly lower abundances compared to the reference and a significant interaction term were, 


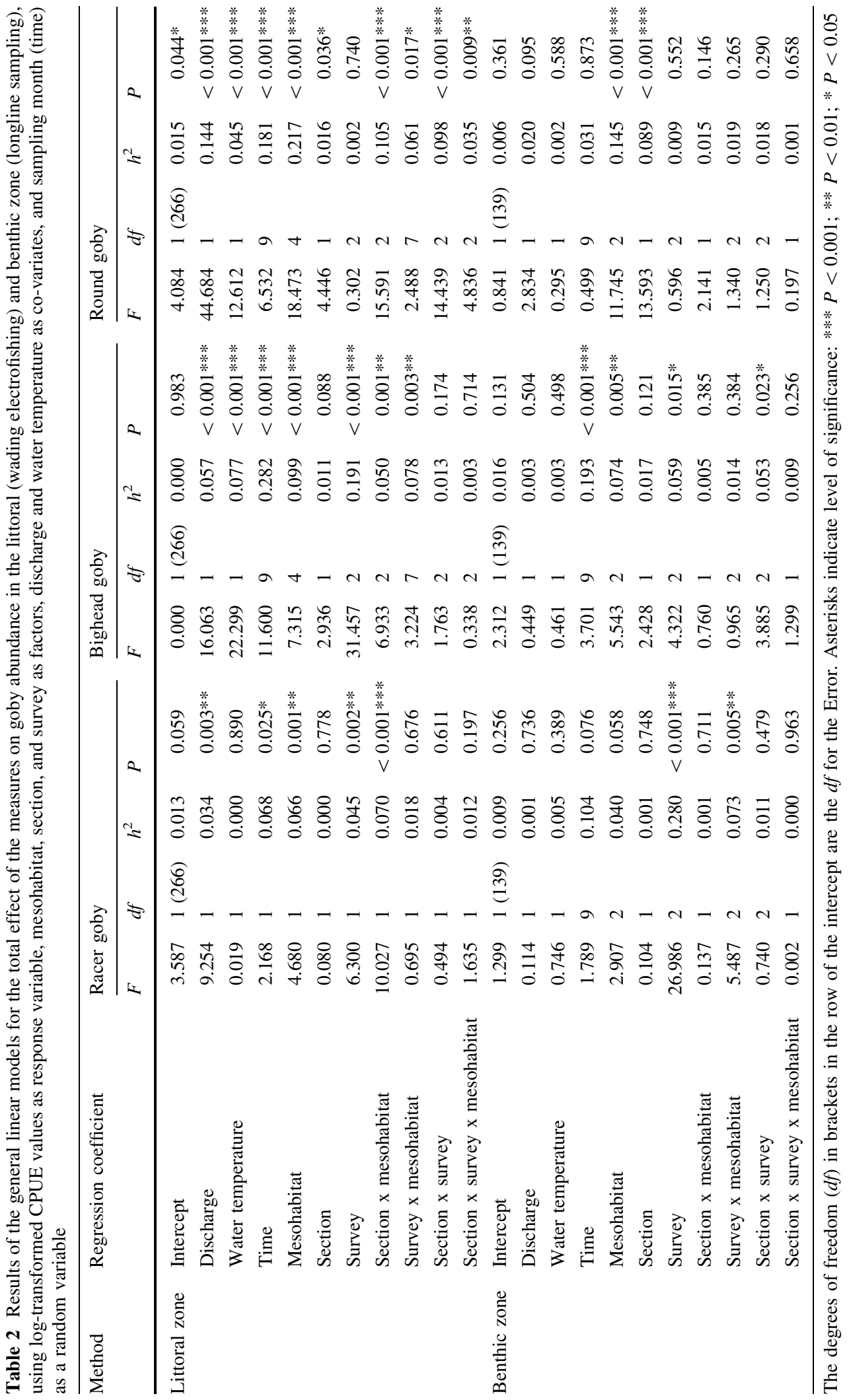




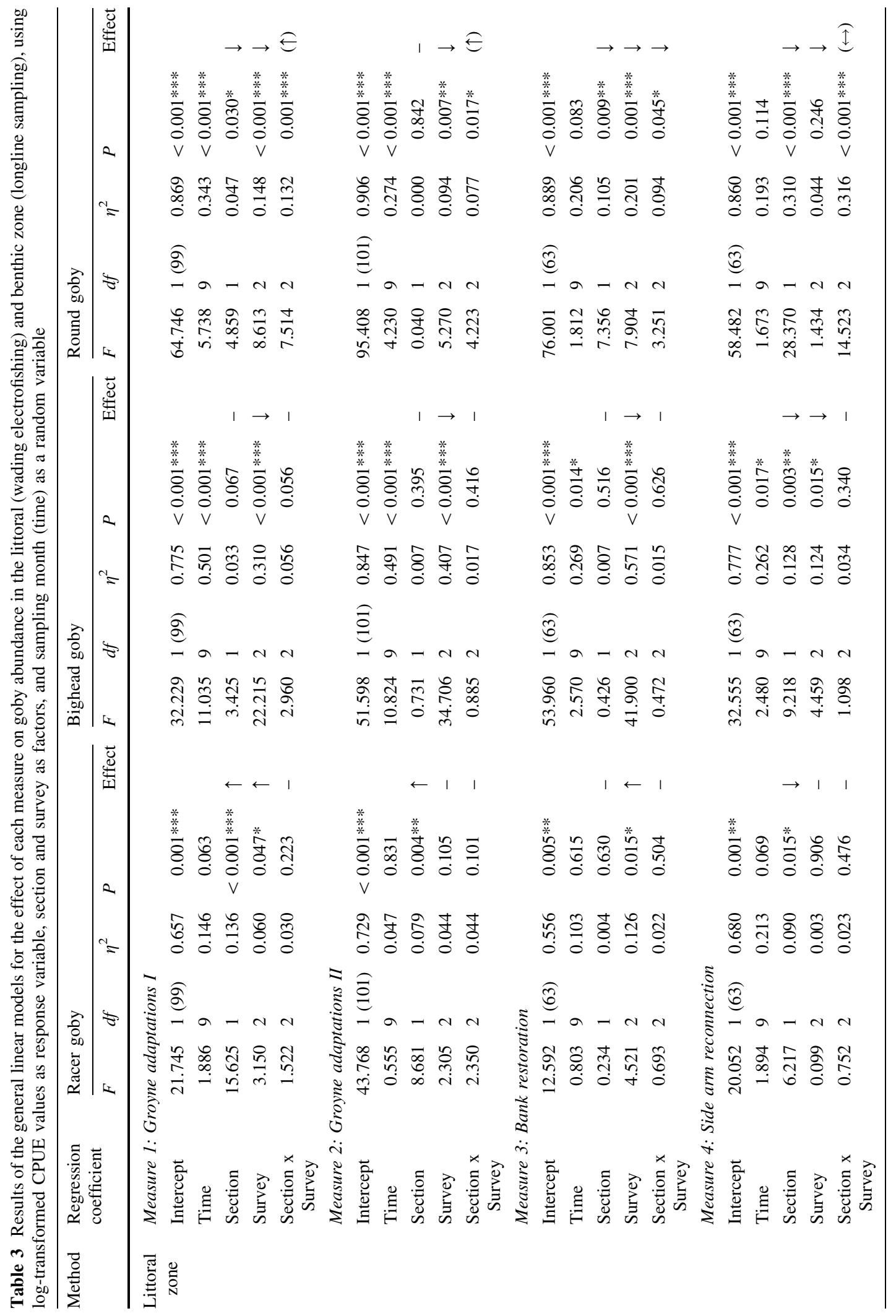




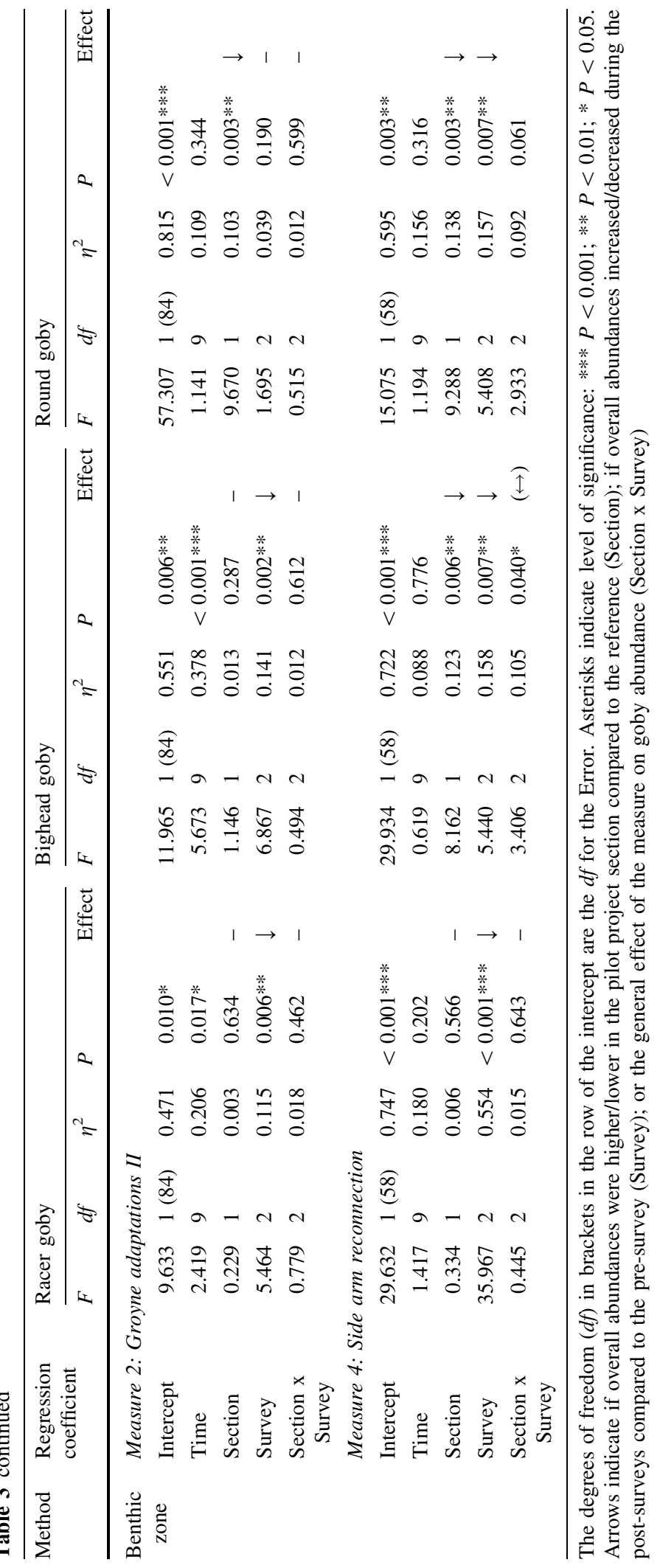


Fig. 3 Abundances of invasive gobies before and after restoration measures 1 and 2 in the littoral (green, left diagrams) and benthic zone (yellow, right diagrams). In measure 1 the former groynefield was converted to a gravel island with a side channel behind it; in measure 2 the groynefield was only modified. Black linemedian; whiskers-25/75 quartiles; dots-5/95 percentiles. PRE—-presurvey in 2006/07; POST1-post-survey 1 in 2014/15; POST2-postsurvey 2 in 2017. M1/M2measure $1 / 2$ implemented in the project section (light); REF-reference sections (dark)

\section{Measures $1+2$ \\ Groyne adaptations I + II}

littoral zone

benthic zone
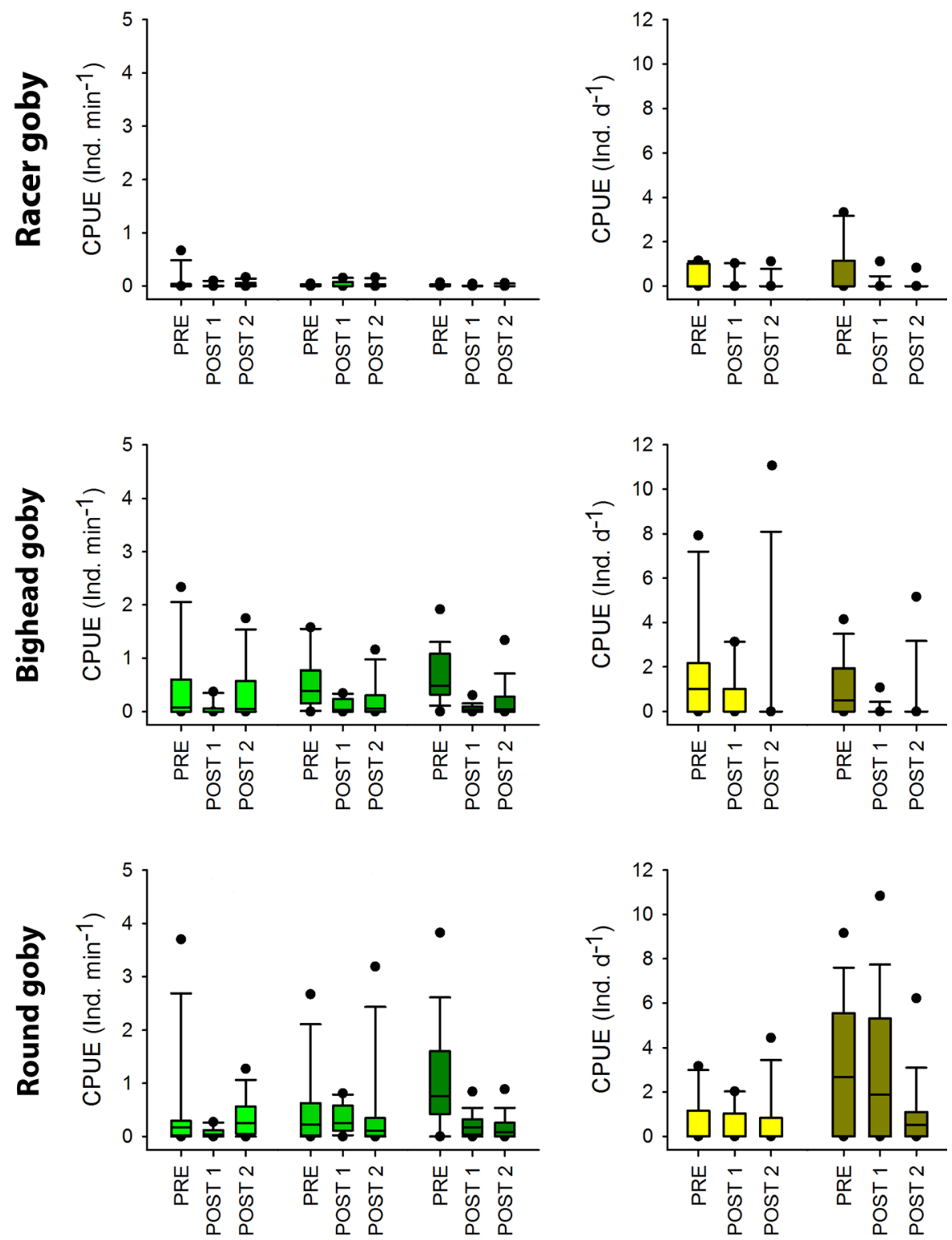

M1

M2

REF

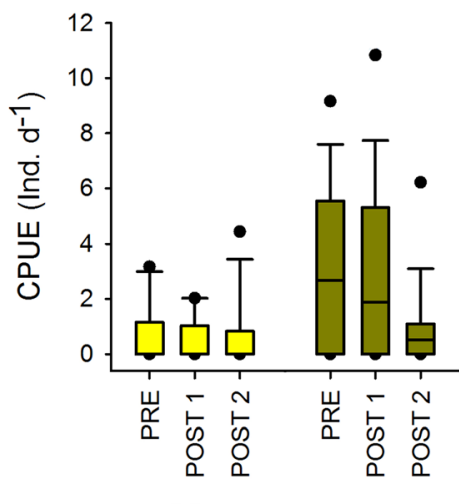

however, only found for round goby, but not for bighead goby. The numbers of racer goby were low before and after the measures, without significant changes (Fig. 4). The effects of the side arm reconnection (measure 4) on goby abundances was generally minimal. Abundances of all three goby species were low or zero in the littoral and benthic zone before and after the reconnection. An exception is the racer goby which showed relatively high abundances during the pre-survey in the benthic zone. Significant interaction terms were found for round goby (littoral) and bighead goby (benthic; Table 3). Goby abundances were generally higher in the reference side arm, especially during the pre-survey, resulting in 
Measure 3

Bank restoration

littoral zone
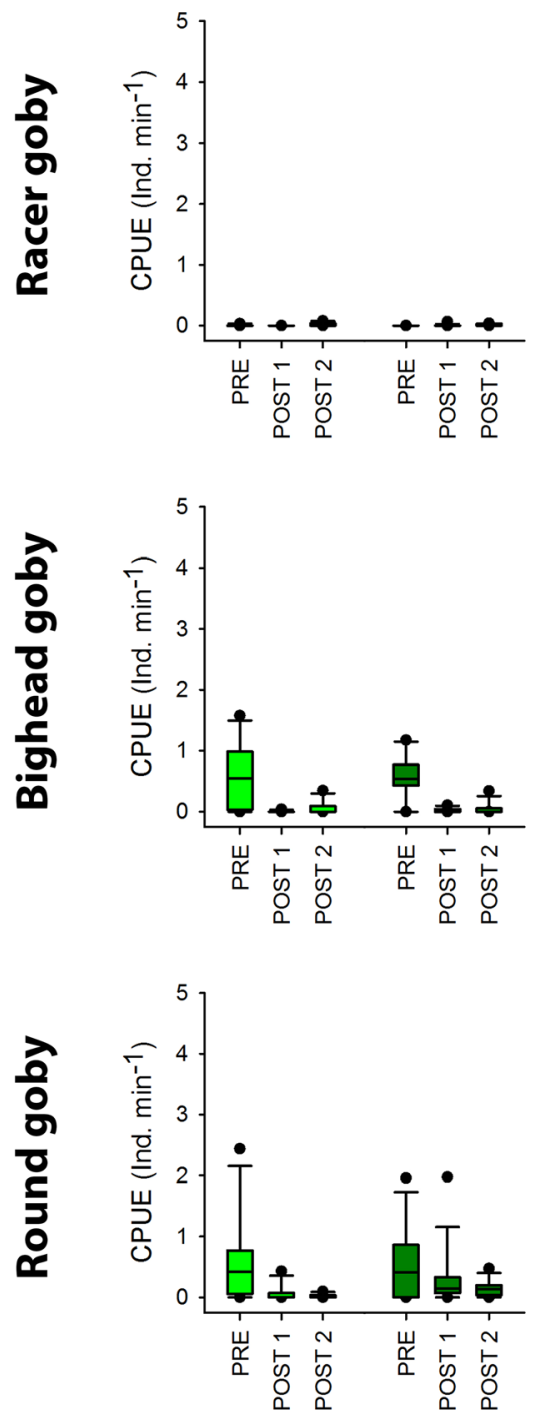

M3

Fig. 4 Abundances of invasive gobies before and after restoration measures 3 and 4 in the littoral (green, left and middle diagrams) and benthic zone (yellow, right diagrams). In measure 3 the former riprap section was replaced by a gravel bar; in measure 4 a former side arm was reconnected to the main

significant differences between sections in most cases (Fig. 4, Tables 2,3).

The effect of the measures on size was variable (Fig. 5, Online Resource 5). For bighead goby a

\section{Measure 4 \\ Side arm reconnection}

littoral zone

benthic zone
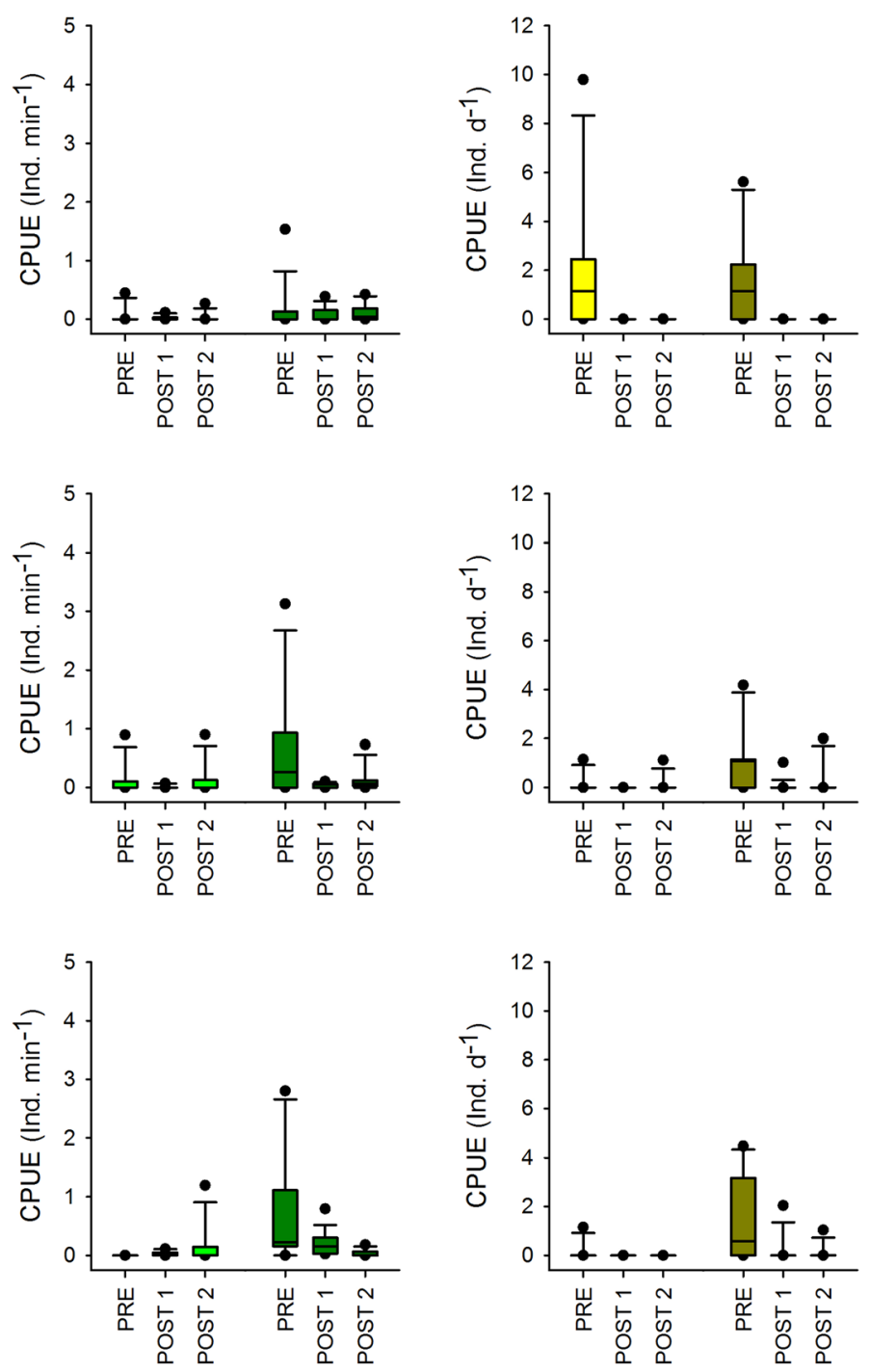

M4

REF

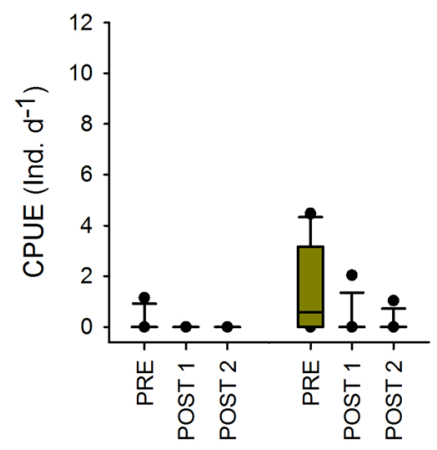

M4

REF

stem. Black line-median; whiskers-25/75 quartiles; dots-5/ 95 percentiles. PRE-pre-survey in 2006/07; POST1-postsurvey 1 in 2014/15; POST2-post-survey 2 in 2017. M3/M4measure $3 / 4$ implemented in the project section (light); REFreference sections (dark)

significant interaction term was found for groyne adaptation I and the side arm reconnection (measure $1+4)$ and for round goby for groyne adaptation I and the bank restoration (measures $1+3$ ). It is apparent 

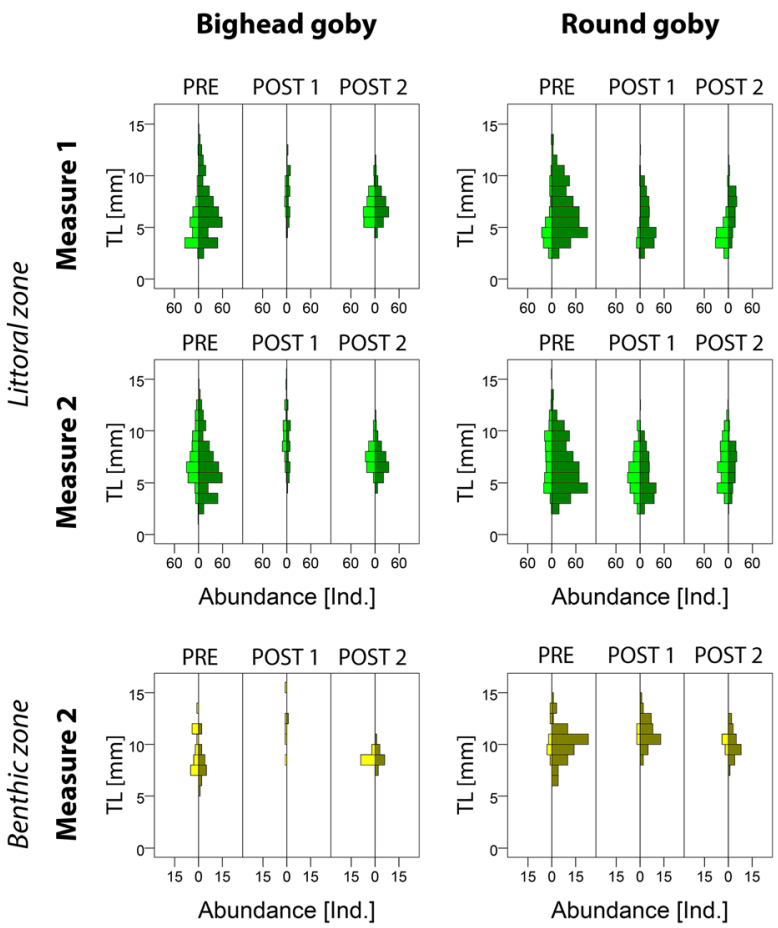

Fig. 5 Size distribution of bighead and round goby before and after the measures in the littoral (green, upper diagrams) and benthic zone (yellow, lower diagrams). Abundances in the project zone (left, lighter colors) are mirrored by the

that smaller round gobies used the side channel during the post-surveys and also the former groynefield during the pre-survey compared to the reference groynefields. The same may be true for the new gravel bar and the reconnected side arm, however, simultaneously also abundances decreased drastically. In bighead goby, the size distribution patterns remained generally similar to the references.

\section{Discussion}

Our study showed that shore restoration measures can be used to limit goby abundances. It depends on the type of measure, though; some measures may also foster goby populations. Restoration projects should therefore carefully consider which measures are implemented. If the goal is to reduce goby abundances, the projects must ensure that an extensive multi-annual monitoring of treatment and reference sections is realized, in order to be able to correctly judge the effectiveness of the measure(s).
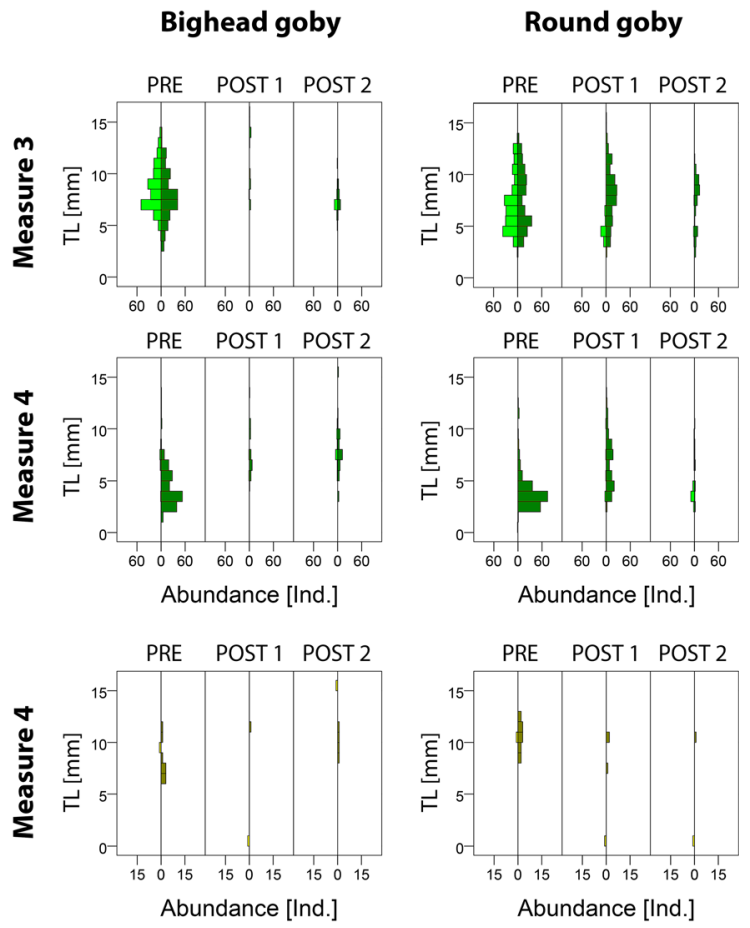

corresponding abundances in the references section (right, darker colors) of each survey. PRE-pre-survey in 2006/07; POST1-post-survey 1 in 2014/15; POST2-post-survey 2 in 2017

\section{General}

Independent of the restoration effects (discussed below), we found a strong general decline in goby abundance in the project and reference sections. There are several potential causes for this decline, which probably also act in combination. First, it may indicate that the population boom following the successful invasion of this part of the Danube in the 1990s is over. Gobies rapidly reproduce and may colonize entire rivers and lakes very soon after the first occurrence (e.g. summarized for round goby in Kornis et al. 2012). In many cases, one or more invasive goby species were among the most common fishes of a given water body within a few years (Borcherding et al. 2011; Jurajda et al. 2005; Szalóky et al. 2015; Wiesner 2005). Due to their sheer numbers and biomass, gobies are not only competitors to native species, but also constitute a potential new food source. Recent research has shown that native predatory species are able to adapt and shift their diet in favor of the ubiquitous gobies, possibly also 
limiting/controlling their spread and abundance (Hempel et al. 2016; Mikl et al. 2017; Płąchocki et al. 2012; Reyjol et al. 2010). Secondly, discharge, and thus the available volume of water, has an effect on the catchability of fishes and therefore influences abundance estimates (e.g. Ramler et al. 2016; Speas et al. 2004). During the pre-survey sampling, the average discharge was lower than at the post-surveys. It is highly improbable, though, that this difference in discharge and water level is the sole cause for the drastic reduction in numbers (up to $-90 \%$ reduction in mean CPUE in post-surveys). Furthermore, the decline is also apparent in the benthic zone (up to $-95 \%$ ), which are not or less affected by discharge (Table 2). Lastly, an extreme flood event in June 2013 (i.e. the year before post-survey 1) in the Upper Danube Basin may have had an impact on gobies. This flood event, with a maximum discharge of ca. $11,000 \mathrm{~m}^{3} \mathrm{~s}^{-1}$ (measured in Vienna), was the most severe flood since centuries (Blöschl et al. 2013), therefore it is plausible that it affected goby (and other species) abundances. The actual response of the fish community to floods is, however, ambiguous (Piniewski et al. 2017). Several studies reported that non-native species showed the most negative response to floods, which is usually explained by a lack of adaptation to flood regimes (Deboer et al. 2011; Piniewski et al. 2017). The non-native species in these studies were primarily salmonids, though. Furthermore, the native range of most invasive gobies also comprised running waters (e.g. Lower Danube, Prut, Siret, Dnieper; Roche et al. 2013), thus, they should not be completely naïve to floods, although this would also depend on where the invasive founding populations originate from. On the other hand, species like burbot (Lota lota), gudgeons (Gobioninae), or sculpins (Cottus spp.), which share many habitat preferences with round and bighead gobies (i.e. benthic, rocky habitats), were found to be not affected by floods or even increased in abundance afterwards (Deboer et al. 2011; Jurajda et al. 2006). Less is known on the effect of floods on early developmental stages, which appears to be also very variable and species-specific (Jurajda et al. 2006; Piniewski et al. 2017). There is indication that gobies react to perturbations by adapting life-history-traits, for instance by increasing oocytes number (Hôrková and Kováč 2015). Furthermore, due to their generally high fecundity, gobies should be able to rapidly compensate population losses. At least for round goby, this was not the case. Accordingly, we suggest that the major flood event was not the main cause for the decline.

Overall, we consider our findings on the general trend of goby abundances to primarily reflect a stabilization on a lower level due to an adaptation of the local fauna (Ramler and Keckeis 2019). Nonetheless, round and bighead goby are still among the most abundant fishes in the sampling area. In any case, our results highlight the importance of a sampling design with reference sections: in the present case, the absence of such a section would have yielded an incorrect interpretation (overestimation) of the effects of the measures.

\section{Effects of restoration measures}

The restoration measures did have an effect on goby occurrence and abundances, ranging from positive, to neutral and negative. The effectiveness was partly species-specific and also linked to the mesohabitat types involved, which were found to be suitable units for analyzing and assessing restoration effects. Although the two groyne field adaptations differed in intensity, the effect on the goby community was surprisingly similar. The removal of large parts of the former groynes and the installation of a gravel island (measure 1) led to a drop of inshore abundances of all gobies during post-survey 1 . In post-survey 2 , however, numbers quickly recovered to equal or even higher magnitudes than during the pre-survey. This could be linked to the flood event in 2013 (see above), on the other hand, this measure was also the last one finished, with the first sampling date of post-survey 1 shortly afterwards. Conceivably, the lower abundances during post-survey 1 may be influenced by shorter colonization possibilities of the modified habitat. Adapting the groynes by cutting the roots and changing the height and position (measure 2) had almost no effect on goby abundance. Also, the size distribution patterns in the project and reference sections were similar in bighead and round gobies throughout all surveys. Apparently, adapting groynes is not a suitable measure to decrease goby abundances, irrespective of intensity. A significant interaction term was only found for round goby, which is, however, primarily due to decreased abundances in the reference section during the post-surveys. Gobies may thus even benefit from these measures. This is surprising 
because side channels can be regarded as intermediate between side arms and gravel bars (concerning abiotic parameters), which are both habitats not preferred by bighead and round gobies. Thus, at least the side channel construction (measure 1) was expected to have a profound impact on them due to the change in substrate composition. However, abundances in a side channel sampled in the reference section were much lower (see also Online Resource 3). This difference of goby abundances in side channels is probably influenced by larger-scale factors such as different types of upstream habitats. In gobies, most dispersal is probably directed downstream, especially during the drift of early life stages, which is known to be an important dispersal mechanism in gobies (Borcherding et al. 2016; Janáč et al. 2013; Ramler et al. 2016). Accordingly, the higher abundance of gobies in the project section may be due to a higher upstream stock of gobies. Our interpretation is that side channels are not preferred habitats of gobies per se, but that goby abundances in this mesohabitat are also influenced by upstream habitat conditions.

Converting a riprap to a gravel bar (measure 3 ) is an appropriate method to reduce the abundance of round gobies. In fact, although all measures had a significant effect on round goby abundance in the littoral zone, this measure was the only one that led to an actual decrease in numbers. Abundances of all three goby species were low or zero in gravel bars during all surveys and all size classes, however, no significant differences between the project and reference section were found for racer and bighead goby. This is because racer gobies were only rarely found in ripraps at all, and the abundances of the latter dropped in this mesohabitat type during the post-surveys in both sections. The reason for this declining trend in bighead gobies is unclear because ripraps are actually readily utilized, often with equal or even higher abundances than round goby (e.g. Borcherding et al. 2011; Janáč et al. 2018). Possible explanations would be increased competition with round goby or increased (and selective) predation, driving bighead gobies to suboptimal habitats. Nevertheless, if the shift in habitat preference is neglected, this measure appears to be also suitable to limit the abundance of bighead gobies.

In the pilot project section, goby abundances in the side arm were low or zero before and after the reconnection (measure 4), although abundances (in the littoral zone) slightly increased again during post- survey 2. This is probably caused by the higher connection of the reconnected side arm with source habitats in the main stem; nonetheless, median abundances were zero for all goby species throughout all surveys. Side arms are avoided by larger bighead and round gobies individuals (although this habitat seems attractive for small individuals; Fig. 5, Online Resource 4B), irrespective of flow conditions, probably due the high amount of fine substrate or macrophytes cover. Racer gobies are known to cope well with the conditions in side arms (Didenko 2013; Jakubčinová et al. 2017; Kakareko et al. 2016) and also showed a preference for this habitat type in the study area regardless of size. This species is far less abundant than the other two gobies in the sampling area and the Upper and Lower Danube in general, which is also linked to its preference for habitats that have become rare (e.g. muddy, vegetated shores; Jakubčinová et al. 2017). Accordingly, it is only of marginal ecological concern. The abundances of all gobies were higher in side arms of the references compared to the pilot project section, especially during the pre-survey. The higher abundances are probably linked to the higher habitat diversity of the reference side arms, which also include parts of the shore stabilized with riprap, making this mesohabitat attractive for all goby species. While abundances remained low in the project section, without any apparent effect of the measure, abundances dropped to low or moderate levels in the reference.

Significant effects of the measures on mean sizes revealed a clear pattern in round goby. Only very small individuals (at or below $5 \mathrm{~cm}$ ) were found in the side channel and gravel bar (measures $1+3$ ) in the project section during both post-surveys and also in the reconnected side arm (measure 4, though without significance in this case). Therefore, although these mesohabitats may be used as nursery habitats, they do not constitute appropriate habitats for older, or rather, larger individuals of round goby (anymore), which are only found in groynefields and ripraps. The high numbers of small round gobies in the side channel may also lead to enhanced recruitment in adjacent areas. In contrasts, the effect of the measures on bighead goby was less consistent. Sizes of bighead gobies tended to increase in both sections during the post-surveys. The significant interaction terms found for bighead goby are probably based on small differences (without biological significance) that were detected because of 
the high number of observations. Generally, the size distribution pattern in the pilot project mirrors that of the reference and are thus not indicating an effect of a measure. It is striking that almost exclusively medium sized bighead gobies $(5-10 \mathrm{~cm})$ were caught during the post-surveys, especially during post-survey 2 , in both sections (Fig. 2b). Apparently, recently hatched bighead gobies must have settled in unsampled habitats. As we sampled a large variety of habitat types, the most likely explanation is a shift to deeper waters, which were inaccessible to wading electrofishing and, due to the small fish size, not effectively sampled by longlines. This shift may reflect increased competition with small round gobies, or size-dependent predation (Płąchocki et al. 2012; Všetičková et al. 2018). Interestingly, Borcherding et al. (2011) and Didenko (2013) also found very few or no small individuals of bighead gobies in samples from the Rhine and Dnieper, respectively. Young gobies are frequently found in the drift, but only in a narrow size range, with most individuals drifting between 6 and 8 mm (Borcherding et al. 2016; Ramler et al. 2016). Larger young fish apparently settle in unknown habitats and reappear later. The whereabouts of young bighead gobies remains obscure, although the findings from the pre-survey suggest that the habitat shift is a relatively recent phenomenon.

\section{Conclusions}

Our study demonstrated that analyzing the effects of hydro-engineering measures for restoration requires intensive, large-scale monitoring efforts, even when focusing on a small group of fishes. Incorrect assessments of measures arise from the omission of reference sections and also a too early cessation of sampling may lead to misleading conclusions. Furthermore, general population trends may mask the effect of restoration efforts.

Our results largely support our assumptions that the restoration measures had different effects on gobies depending on type of measure and species. Bank restoration, by replacing a riprap with a gravel bar, was found to be the most suitable measure to lower the abundance of round and likely also bighead gobies. The side arm reconnection had little effect on gobies, however, abundances were generally low before and after the measure. Both measures can therefore be recommended without restriction. Groyne adaptations, on the other hand, were unable to limit goby abundances and may even be beneficial for gobies, and can thus not be recommended in cases where high goby abundances are deemed problematic.

The effect on invasive species is only one element in judging restoration success, which needs to be evaluated against, and compared with, the effect on the native fauna or target species of restoration. Nonetheless, invasive species can pose a major threat to native communities, yet direct management options are often limited. Our study exemplified that restoration measures can be used for population control of invasive gobies and suggest that they are incorporated in the planning and implementation of future restoration projects.

Acknowledgements Open access funding provided by University of Vienna. The pilot project Bad DeutschAltenburg was commissioned and financed by the viadonau Österreichische Wasserstraßen-Gesellschaft $\mathrm{mbH}$ and the Federal Ministry for Transport, Innovation and Technology. Fish sampling was granted by the Lower Austrian Fishery Association (BNÖ LFV-E-04/12 NÖ Landesfischereiverband). We thank the Gutsverwaltung Petronell, the municipality and fishermen association of Hainburg, and the Nationalpark Donau-Auen $\mathrm{GmbH}$ for sampling permissions. We also like to extend thanks to Elisabeth Schludermann, Dominik Altmann, Vinzenz Bammer, Simon Götsch, Hansjörg Hoyer, Tim Kaminskas, Franz Lumesberger-Loisl, Reinhard Krusch, Maximilian Sehr, Astrid Toth, Holger Villwock, Bernhard Zens, Philip Kerschbaumer, Michael Schöfbenker, Sylvia Wanzenböck and Julia Weber for their participation in sampling and data entry. Michael Stachowitsch has improved the English.

Open Access This article is distributed under the terms of the Creative Commons Attribution 4.0 International License (http:// creativecommons.org/licenses/by/4.0/), which permits unrestricted use, distribution, and reproduction in any medium, provided you give appropriate credit to the original author(s) and the source, provide a link to the Creative Commons license, and indicate if changes were made.

\section{References}

Ahnelt H (1988) Zum Vorkommen der Marmorierten Grundel (Proterorhinus marmoratus (Pallas), Pisces: Gobiidae) in Österreich. Annalen des Naturhistorischen Museums in Wien 90:31-42

Ahnelt H, Banarescu P, Spolwind R, Harka A, Waidbacher H (1998) Occurrence and distribution of three gobiid species (Pisces, Gobiidae) in the middle and upper Danube region- 
examples of different dispersal patterns? Biol Bratisl 53:665-678

Blöschl G, Nester T, Komma J, Parajka J, Perdigão RAP (2013) The June 2013 flood in the Upper Danube Basin, and comparisons with the 2002, 1954 and 1899 floods. Hydrol Earth Syst Sci 17:5197-5212

Borcherding J, Staas S, Krüger S, Ondračková M, Šlapanský L, Jurajda P (2011) Non-native Gobiid species in the lower River Rhine (Germany): recent range extensions and densities. J Appl Ichthyol 27:153-155

Borcherding J, Dolina M, Heermann L, Knutzen P, Krüger S, Matern S, van Treeck R, Gertzen S (2013) Feeding and niche differentiation in three invasive gobies in the Lower Rhine, Germany. Limnol Ecol Manag Inland Waters 43:49-58

Borcherding J, Arndt H, Breiden S et al (2016) Drift of fish larvae and juveniles in the Lower Rhine before and after the goby invasion. Limnologica 59:53-62

Brandner J, Cerwenka AF, Schliewen UK, Geist J (2013) Bigger is better: characteristics of round gobies forming an invasion front in the Danube River. PLoS ONE 8:e73036

Charlebois PM, Corkum LD, Jude DJ, Knight C (2001) The round goby (Neogobius melanostomus) invasion: current research and future needs. J Great Lakes Res 27:263-266

Deboer JA, Ogren SA, Holtgren JM, Snyder EB (2011) A 100-year flood in a low-gradient stream: response of the resident and non-resident fish assemblages. Am Midl Nat $166: 446-452$

Didenko AV (2013) Gobiids of the Dniprodzerzhynsk reservoir (Dnieper river, Ukraine): distribution and habitat preferences. Acta Ichthyol Piscat 43:257-266

Dorenbosch M, van Kessel N, Liefveld W, Schoor M, van der Velde G, Leuven RSEW (2017) Application of large wood in regulated riverine habitats facilitates native fishes but not invasive alien round goby (Neogobius melanostomus). Aquat Invasions 12:405-413

Erös T, Sevcsik A, Tóth B (2005) Abundance and night-time habitat use patterns of Ponto-Caspian gobiid species (Pisces, Gobiidae) in the littoral zone of the River Danube, Hungary. J Appl Ichthyol 21:350-357

Gozlan RE, Britton JR, Cowx I, Copp GH (2010) Current knowledge on non-native freshwater fish introductions. J Fish Biol 76:751-786

Hempel M, Neukamm R, Thiel R (2016) Effects of introduced round goby (Neogobius melanostomus) on diet composition and growth of zander (Sander lucioperca), a main predator in European brackish waters. Aquat Invasions 11:167-178

Hôrková K, Kováč V (2015) Rapid response of invasive round goby (Neogobius melanostomus) (Pallas, 1814) to an environmental perturbation demonstrated in reproductive parameters of females. J Appl Ichthyol 31:328-332

Jakubčinová K, Simonović P, Števove B, Čanak Atlagić J, Kováč V (2017) What can morphology tell us about ecology of four invasive goby species? J Fish Biol 90:1999-2019

Janáč M, Šlapanský L, Valová Z, Jurajda P (2013) Downstream drift of round goby (Neogobius melanostomus) and tubenose goby (Proterorhinus semilunaris) in their non-native area. Ecol Freshw Fish 22:430-438
Janáč M, Valová Z, Roche K, Jurajda P (2016) No effect of round goby Neogobius melanostomus colonisation on young-of-the-year fish density or microhabitat use. Biol Invasions 18:2333-2347

Janáč M, Roche K, Šlapanský L, Polačik M, Jurajda P (2018) Long-term monitoring of native bullhead and invasive gobiids in the Danubian rip-rap zone. Hydrobiologia 807:263-275

Janssen J, Jude DJ (2001) Recruitment failure of mottled sculpin Cottus bairdi in Calumet Harbor, southern Lake Michigan, induced by the newly introduced round goby Neogobius melanostomus. J Great Lakes Res 27:319-328

Jermacz Ł, Kobak J, Dzierżyńska A, Kakareko T (2015) The effect of flow on the competition between the alien racer goby and native European bullhead. Ecol Freshw Fish 24:467-477

Jurajda P, Černý J, Polačik M, Valová Z, Janáč M, Blažek R, Ondračková M (2005) The recent distribution and abundance of non-native Neogobius fishes in the Slovak section of the River Danube. J Appl Ichthyol 21:319-323

Jurajda P, Reichard M, Smith C (2006) Immediate impact of an extensive summer flood on the adult fish assemblage of a channelized lowland river. J Freshw Ecol 21:493-501

Kakareko T, Kobak J, Poznańska M, Jermacz Ł, Copp GH (2016) Underwater evaluation of habitat partitioning in a European river between a non-native invader, the racer goby and a threatened native fish, the European bullhead. Ecol Freshw Fish 25:60-71

Kornis MS, Mercado-Silva N, Vander Zanden M (2012) Twenty years of invasion: A review of round goby Neogobius melanostomus biology, spread and ecological implications. J Fish Biol 80:235-285

Kornis MS, Sharma S, Vander Zanden MJ (2013) Invasion success and impact of an invasive fish, round goby, in Great Lakes tributaries. Divers Distrib 19:184-198

Kováč V, Copp G, Sousa R (2009) Life-history traits of invasive bighead goby Neogobius kessleri (Gunther, 1861) from the middle Danube River, with a reflection on which goby species may win the competition. J Appl Ichthyol 25:33-37

Kubečka J, Godø OR, Hickley P, Prchalová M, Ríha M, Rudstam L, Welcomme R (2012) Fish sampling with active methods. Fish Res 123-124:1-3

Loisl F, Singer G, Keckeis H (2014) Method-integrated fish assemblage structure at two spatial scales along a freeflowing stretch of the Austrian Danube. Hydrobiologia 729:77-94

Mahlum S, Cote D, Wiersma YF, Pennell C, Adams B (2018) Does restoration work? It depends on how we measure success. Restor Ecol 26:952-963

McCune B, Grace JB, Urban DL (2002) Analysis of ecological communities. MjM Software, Gleneden Beach, OR

Mikl L, Adámek Z, Roche K, Všetičková L, Šlapanský L, Jurajda P (2017) Invasive Ponto-Caspian gobies in the diet of piscivorous fish in a European lowland river. Fundam Appl Limnol/Archiv für Hydrobiologie 190:157-171

Moog O, Chovanec A, Hinteregger J, Römer A (1999) Richtlinie zur Bestimmung der saprobiologischen Gewässergüte von Fliessgewässern. Bundesministerium für Landund Forstwirtschaft, Vienna

N'Guyen A, Hirsch PE, Bozzuto C, Adrian-Kalchhauser I, Hôrková K, Burkhardt-Holm P, Zenni R (2018) A 
dynamical model for invasive round goby populations reveals efficient and effective management options. J Appl Ecol 55:342-352

Piniewski M, Prudhomme C, Acreman MC, Tylec L, Oglęcki P, Okruszko T (2017) Responses of fish and invertebrates to floods and droughts in Europe. Ecohydrology 10:e1793

Piria M, Jakšić G, Jakovlić I, Treer T (2016) Dietary habits of invasive Ponto-Caspian gobies in the Croatian part of the Danube River basin and their potential impact on benthic fish communities. Sci Total Environ 540:386-395

Płąchocki D, Kobak J, Kakareko T (2012) First report on the importance of alien gobiids in the diet of native piscivorous fishes in the lower Vistula River (Poland). Oceanol Hydrobiol Stud 41:83-89

Polačik M, Janáč M, Trichkova T, Vassilev M, Keckeis H, Jurajda P (2008) The distribution and abundance of the Neogobius fishes in their native range (Bulgaria) with notes on the non-native range in the Danube River. Large Rivers 18:193-208

Ramler D, Keckeis H (2018) Erste Ergebnisse des Fischmonitorings im Rahmen des Flussbaulichen Gesamtprojekts östlich von Wien: Ein Überblick. Österreichs Fischerei 71:89-101

Ramler D, Keckeis H (2019) Occurrence of non-native fishes in the Danube east of Vienna (Austria) and potential interactions of invasive gobiids with native fishes. J Appl Ichthyol 00:1-13

Ramler D, Ahnelt H, Nemeschkal HL, Keckeis H (2016) The drift of early life stages of Percidae and Gobiidae (Pisces: Teleostei) in a free-flowing section of the Austrian Danube. Hydrobiologia 781:199-216

Ray WJ, Corkum LD (2001) Habitat and site affinity of the round goby. J Great Lakes Res 27:329-334

Reckendorfer W, Schmalfuss R, Baumgartner C, Habersack H, Hohensinner S, Jungwirth M, Schiemer F (2005) The Integrated River Engineering Project for the free-flowing Danube in the Austrian Alluvial Zone National Park: contradictory goals and mutual solutions. Large Rivers 15:613-630

Reyjol Y, Brodeur P, Mailhot Y, Mingelbier M, Dumont P (2010) Do native predators feed on non-native prey? The case of round goby in a fluvial piscivorous fish assemblage. J Great Lakes Res 36:618-624
Ricciardi A, MacIsaac HJ (2000) Recent mass invasion of the North American Great Lakes by Ponto-Caspian species. Trends Ecol Evol 15:62-65

Roche KF, Janač M, Jurajda P (2013) A review of Gobiid expansion along the Danube-Rhine corridor-geopolitical change as a driver for invasion. Knowl Manag Aquat Ecosyst 411:23

Smith EP (2002) BACI design. In: El-Shaarawi AH, Piegorsch WW (eds) Encyclopedia of environmetrics. Wiley, Chichester, pp 141-148

Speas DW, Walters CJ, Ward DL, Rogers RS (2004) Effects of intraspecific density and environmental variables on electrofishing catchability of brown and rainbow trout in the Colorado River. N Am J Fish Manag 24:586-596

Števove B, Kováč V (2016) Ontogenetic variations in the diet of two invasive gobies, Neogobius melanostomus (Pallas, 1814) and Ponticola kessleri (Günther, 1861), from the middle Danube (Slovakia) with notice on their potential impact on benthic invertebrate communities. Sci Total Environ 557-558:510-519

Szalóky Z, Bammer V, György ÁI, Pehlivanov L, Schabuss M, Zornig H, Weiperth A, Eros T (2015) Offshore distribution of invasive gobies (Pisces: Gobiidae) along the longitudinal profile of the Danube River. Fundam Appl Limnol/ Archiv für Hydrobiologie 187:127-133

van Kessel N, Dorenbosch M, de Boer MRM, Leuven RSEW, van der Velde $G$ (2011) Competition for shelter between four invasive gobiids and two native benthic fish species. Curr Zool 57:844-851

Všetičková L, Mikl L, Adámek Z, Prášek V, Roche K, Jurajda P (2018) The diet of reservoir perch before, during and after establishment of non-native tubenose goby. Knowl Manag Aquat Ecosyst 419:8

Wiesner C (2005) New records of non-indigenous gobies (Neogobius spp.) in the Austrian Danube. J Appl Ichthyol 21:324-327

Publisher's Note Springer Nature remains neutral with regard to jurisdictional claims in published maps and institutional affiliations. 